\title{
Simultaneous Estimation of Ibuprofen and Phenylephrine Hydrochloride in Bulk and Combined Dosage Form by First Derivative UV Spectrophotometry Method
}

\author{
Mehul Patel, Bhavna Patel, and Shraddha Parmar \\ P.G. Department of Pharmaceutical Sciences, Sardar Patel University, Vallabh Vidyanagar, Gujarat 388120, India \\ Correspondence should be addressed to Mehul Patel; mnpatel87@gmail.com
}

Received 29 May 2013; Accepted 24 June 2013

Academic Editor: Damien Boyer

Copyright (c) 2013 Mehul Patel et al. This is an open access article distributed under the Creative Commons Attribution License, which permits unrestricted use, distribution, and reproduction in any medium, provided the original work is properly cited.

A simple, precise, rapid, and economic method was developed for the simultaneous determination of Ibuprofen and Phenylephrine $\mathrm{HCl}$ in bulk and combined dosage form. This method involves first-order derivative spectroscopy using $248 \mathrm{~nm}$ and $237 \mathrm{~nm}$ as zero crossing points for Ibuprofen and Phenylephrine $\mathrm{HCl}$, respectively. For spectrophotometric method $0.1 \mathrm{~N} \mathrm{NaOH}$ was used as a solvent. The linearity was established over the concentration range of $12-72 \mu \mathrm{g} / \mathrm{mL}$ and $1.5-22 \mu \mathrm{g} / \mathrm{mL}$ for Ibuprofen and Phenylephrine $\mathrm{HCl}$ with correlation coefficient $\left(r^{2}\right)$ of 0.9972 and 0.9981 , respectively. The mean \% recoveries were found to be in the range of $98.88 \%$ and $98.54 \%$ for Ibuprofen and Phenylephrine $\mathrm{HCl}$, respectively. Interday and intraday studies showed repeatability of the method. The method was found to be specific and robust. The method was successfully applied to pharmaceutical formulation, with no interference from excipients as indicated by the recovery study. Results of analysis were validated statistically and by recovery studies.

\section{Introduction}

The 2-arylpropionic acid derivative, Ibuprofen [RS-2-(4isobutyl-phenyl) propionic acid], is one of the most potent orally active antipyretic, analgesic, and nonsteroidal antiinflammatory drugs (NSAID)s used extensively in the treatment of acute and chronic pain, osteoarthritis, rheumatoid arthritis, and related conditions. This compound is characterized by a better tolerability compared with other NSAIDs [1]. Ibuprofen contains a chiral carbon atom on the propionic acid side-chain; therefore it exists as two enantiomers. It is usually marketed as a 50:50 mixture of the S- and Renantiomers, even if it is known that the pharmacological activity is due almost exclusively to the S-enantiomer [2].

Phenylephrine Hydrochloride is [(R)-2-methylamino1-(3-hydroxyphenyl) ethanol hydrochloride] and used as alpha-adrenergic, sympathomimetic agent as well as vasoconstrictor with little effect on the myocardium or the central nervous system. The literature survey revealed that spectrophotometry [1], RP-HPLC [2], electrophoresis [3], and liquid chromatography [4] methods have been reported for the estimation of phenylephrine hydrochloride in pharmaceutical formulations. The combination of Ibuprofen (IBU) and Phenylephrine $\mathrm{HCl}$ (PHE) is available as a tablet formulation in the ratio $200: 10 \mathrm{mg}$ IBU : PHE.

RP-HPLC, HPTLC, and spectrophotometric methods for estimation of Ibuprofen (IBU) in combination with other drugs are reported [5-10]. The literature survey also revealed the report of RP-HPLC, HPTLC, and spectrophotometric methods for estimation of Phenylephrine $\mathrm{HCl}$ (PHE) in combination with other drugs [11-15]. As, no UV Spectrophotometric method was developed for the simultaneous estimation of Ibuprofen and Phenylephrine Hydrochloride, so the aim of the study was to develop and validate first-order derivative UV spectrophotometric method for simultaneous estimation of Ibuprofen and Phenylephrine Hydrochloride in bulk and combined dosage form. Chemical structures of IBU and PHE are included in Figure 1.

\section{Materials and Methods}

2.1. Reagents and Chemicals. Analytically pure Ibuprofen and Phenylephrine Hydrochloride were used. Tablets of 
<smiles>CCCCCCCCC(C)Cc1ccc(C(C)C(=O)O)cc1</smiles>

(a)

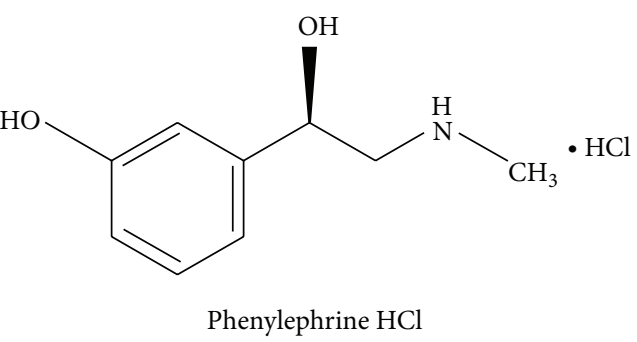

(b)

FIgure 1: Chemical structure of (a) IBU and (b) PHE.

Ibuprofen and Phenylephrine Hydrochloride in combine dosage form with $200 \mathrm{mg}$ IBU and $10 \mathrm{mg}$ PHE label claim were procured.

2.2. Instrument. The spectrophotometer used for study is Shimadzu UV/Vis 1800 double beam spectrophotometer with wavelength accuracy $( \pm 0.3 \mathrm{~nm}), 1 \mathrm{~cm}$ matched quartz cells, and UV probe 2.35 software was used for all the spectral measurements. Calibrated analytical balance Denver SI234, Germany, was used for weighing purpose. All statistical calculations were carried out using Microsoft excel 2010 analytical tool.

2.3. Materials. Standard sample of Ibuprofen and Phenylephrine $\mathrm{HCl}$ was provided by college. Tablets of Ibuprofen and Phenylephrine Hydrochloride in combined dosage form with $200 \mathrm{mg}$ IBU and $10 \mathrm{mg}$ PHE label claim was procured.

2.4. Solvent. An amount of $0.1 \mathrm{~N} \mathrm{NaOH}$ was used as solvent. AR grade $\mathrm{NaOH}$ was used.

2.5. Preparation of Standard Stock Solution. Accurately weighed quantity of IBU and PHE $10 \mathrm{mg}$ was transferred into $10 \mathrm{~mL}$ volumetric flask, dissolved, and diluted up to mark with $0.1 \mathrm{~N} \mathrm{NaOH}$. Standard stock solutions of IBU $(1000 \mu \mathrm{g} / \mathrm{mL})$ and PHE $(1000 \mu \mathrm{g} / \mathrm{mL})$ were obtained which were used for the analysis.

\section{Procedure}

3.1. First-Order Derivative Spectroscopy. In this method solutions of IBU and PHE were prepared separately by appropriate dilution of standard stock solution and scanned in the spectrum mode from $400 \mathrm{~nm}$ to $200 \mathrm{~nm}$. The absorption spectra thus obtained were derivatized to first order. From the spectra of both drugs IBU and PHE (Figure 2), wavelengths were selected for quantitation, $237 \mathrm{~nm}$ for IBU (zero cross for PHE) and $248 \mathrm{~nm}$ for PHE (zero cross for IBU). The calibration curves for IBU and PHE were plotted in the concentration range of $12-72 \mu \mathrm{g} / \mathrm{mL}$ and $1.5-22 \mu \mathrm{g} / \mathrm{mL}$, respectively. The concentration of the individual drug present in the mixture was determined against the calibration curve in quantitation mode.

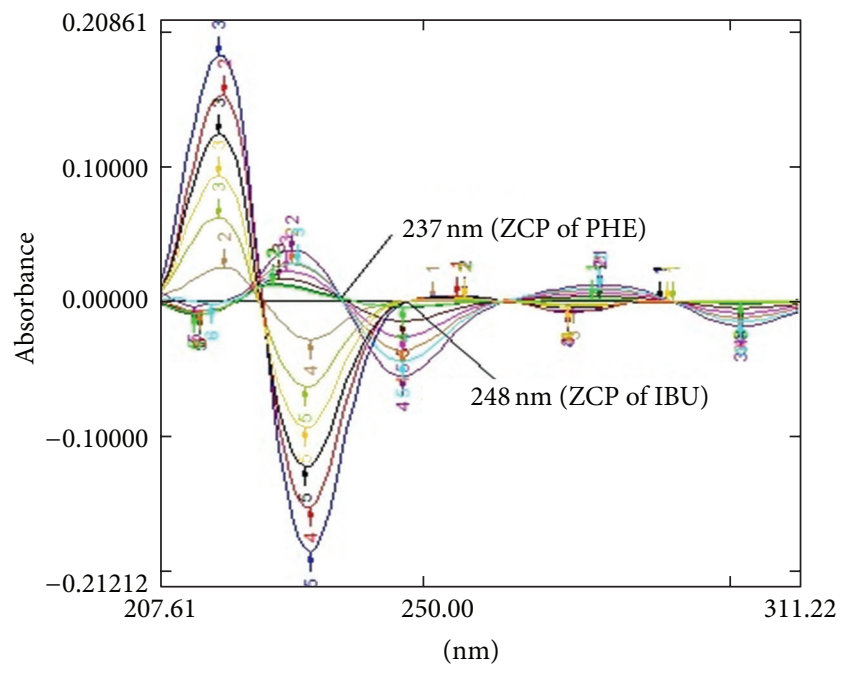

FIGURE 2: Overlain $\mathrm{D}^{1}$ spectrum of IBU (12-72 ppm) and PHE (1.5$22 \mathrm{ppm}$ ) in $0.1 \mathrm{~N} \mathrm{NaOH}$.

3.2. Analysis of Tablet Formulation. Twenty tablets were weighed and average weight was calculated. The tablets were triturated to obtain fine powder. Tablet powder equivalent to $30 \mathrm{mg}$ of IBU and $1.5 \mathrm{mg}$ PHE was transferred to $50.0 \mathrm{~mL}$ volumetric flask, $30 \mathrm{~mL} 0.1 \mathrm{~N} \mathrm{NaOH}$ solution was added, ultrasonicated for 10 minutes, and volume was made up to the mark with the same. From this target concentration prepared was $30 \mathrm{ppm}$ and $1.5 \mathrm{ppm}$. The concentrations of both IBU and PHE were determined by measuring the absorbance of the sample at $237 \mathrm{~nm}$ and $248 \mathrm{~nm}$ in first-order spectrum mode, respectively. The results of the tablet analysis were calculated against the calibration curve in quantitation mode.

\section{Validation}

Method validation parameters like linearity, intraday and interday precision, limit of detection, limit of quantification, accuracy, specificity, and robustness were performed as per $\mathrm{ICH}$ guidelines.

4.1. Linearity. Linearity was observed over a concentration range $12-72 \mu \mathrm{g} / \mathrm{mL}$ and $1.5-22 \mu \mathrm{g} / \mathrm{mL}$ for IBU and PHE, respectively, when measured at the wavelengths $237.0 \mathrm{~nm}$ 
TABLE 1: Results of analysis of tablet formulation.

\begin{tabular}{lcccc}
\hline Drugs & Label claim $(\mathrm{mg})$ & $\begin{array}{c}\text { Amount of drug } \\
\text { estimated }(\mathrm{mg} / \mathrm{tab})\end{array}$ & \% Label claim (\%) \pm S.D. & \% Recovery $^{*}$ \\
\hline IBU & 200 & 198.45 & $99.22 \pm 0.0009107$ & $98.88 \%$ \\
PHE & 10 & 09.82 & $98.20 \pm 0.0007371$ & $98.54 \%$ \\
\hline
\end{tabular}

${ }^{*}$ Average of 3 determination.

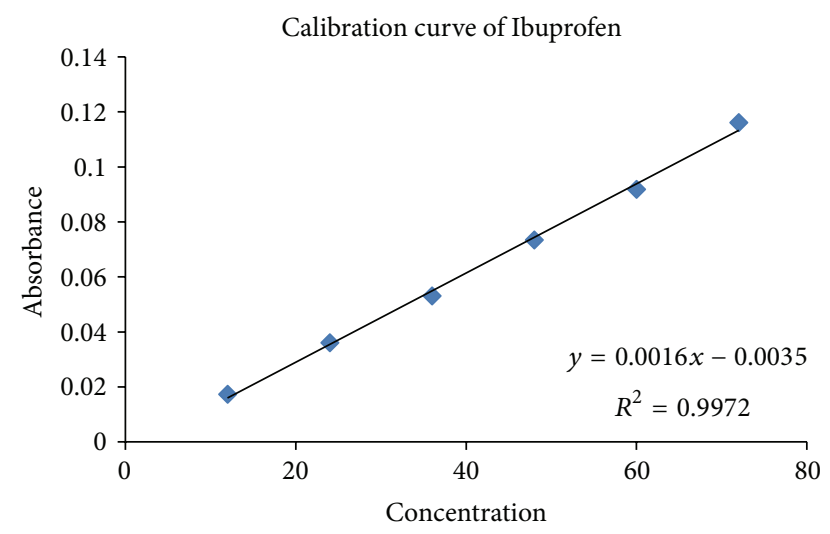

FIgURE 3: Calibration curve of Ibuprofen.

(ZCP of PHE) and $248 \mathrm{~nm}$ (ZCP of IBU). Calibration curves were constructed for IBU and PHE by plotting absorbance versus concentrations at both wavelengths. Each reading was average of three determinations.

4.2. Accuracy (\% Recovery). Accuracy of the developed method was confirmed by recovery study as per ICH guidelines at three different concentration levels of $80 \%, 100 \%$, and $120 \%$ by replicate analysis $(n=3)$. Here to a preanalysed sample solution, standard drug solutions were added and then percentage drug content was calculated. The recovery study indicates that the method is accurate for quantitative estimation of Ibuprofen and Phenylephrine $\mathrm{HCl}$ in tablet dosage form as the statistical results are within the acceptance range (S.D. <2.0).

4.3. Precision. The intraday and interday precision study of IBU and PHE was carried out by estimating different concentrations of IBU $(24,36$, and, $48 \mu \mathrm{g} / \mathrm{mL})$ and PHE ( 6 , 10 , and, $14 \mu \mathrm{g} / \mathrm{mL}$ ), three times on the same day and on three different days, and the results are reported in terms of \% RSD.

4.4. Limit of Detection and Limit of Quantification. The limit of detection (LOD) and the limit of quantification (LOQ) of the drug were derived from the calibration curves by using the following equations as per International Conference on Harmonization (ICH) guidelines:

$$
\begin{aligned}
& \mathrm{LOD}=3.3 \times \frac{\sigma}{S}, \\
& \mathrm{LOQ}=10 \times \frac{\sigma}{S},
\end{aligned}
$$

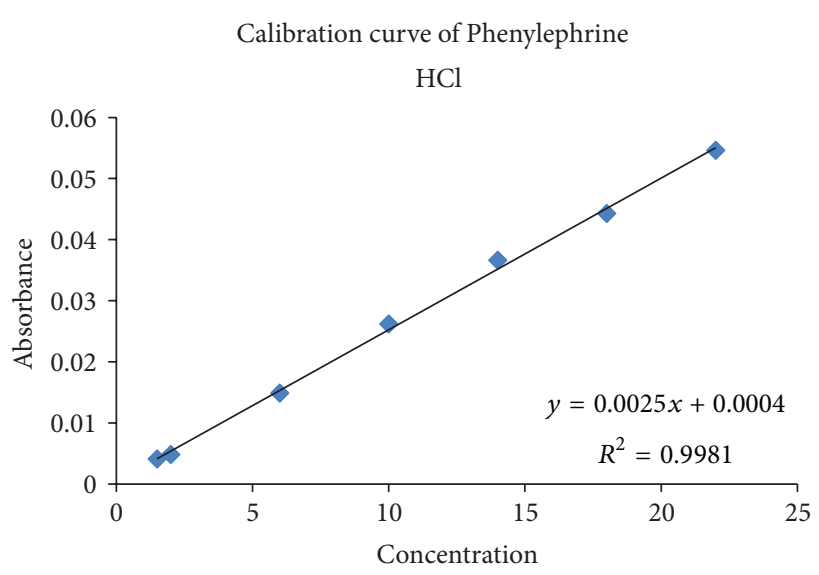

FIgURE 4: Calibration curve of Phenylephrine HCL.

where $\sigma$ is the standard deviation of the response, and $S$ is Slope of calibration curve.

4.5. Specificity. The specificity of an analytical method is ability to measure accurately an analyte in presence of interferences like synthetic precursor, excipients, degradants, or matrix component. Comparison of first derivative UV spectrum of standard mixture and formulation shows specificity of method. The derivative spectrophotometric method is able to access the analyte in presence of excipients, and, hence, it can be considered specific.

4.6. Robustness. The robustness of an analytical method is a measure of its capacity to remain unaffected by small but deliberate variations in method parameters and provides an indication of its reliability during normal usage.

\section{Results and Discussion}

For this method, $237.0 \mathrm{~nm}$ (zero crossing point of PHE) and $248 \mathrm{~nm}$ (zero crossing point of IBU) of first-order derivative spectra were selected for the analysis. Linear relationship was obtained over the range of $12-72 \mu \mathrm{g} / \mathrm{mL}$ and $1.5-22 \mu \mathrm{g} / \mathrm{mL}$ for Ibuprofen and Phenylephrine $\mathrm{HCl}$, respectively (Figures 3 and 4). The correlation coefficients $\left(r^{2}\right)$ for IBU and PHE were found to be 0.9972 and 0.9981 , respectively.

Absorption of IBU at ZCP of PHE and absorption of PHE at $\mathrm{ZCP}$ of $\mathrm{CAF}$ was taken (Figures 5 and 6 ). The $\%$ assay \pm S.D. were found to be $99.22 \pm 0.0009$ for IBU \& $98.20 \pm 0.0007$ for PHE, respectively (Table 1). No interference was observed from the pharmaceutical excipients. For IBU and PHE the 
TABLE 2: Results of recovery studies (tablet).

\begin{tabular}{|c|c|c|c|c|c|c|c|c|}
\hline \% Level & $\begin{array}{c}\text { Amt. of IBU } \\
\text { taken in } \\
\mu \mathrm{g} / \mathrm{mL}\end{array}$ & $\begin{array}{c}\text { Amt. of PHE } \\
\text { taken in } \\
\mu \mathrm{g} / \mathrm{mL}\end{array}$ & $\begin{array}{c}\text { Amt. of Std } \\
\text { IBU added in } \\
\mu \mathrm{g} / \mathrm{mL}\end{array}$ & $\begin{array}{l}\text { Amt. of Std } \\
\text { PHE added } \\
\text { in } \mu \mathrm{g} / \mathrm{mL}\end{array}$ & $\begin{array}{c}\text { \% Recovery } \\
\text { (IBU) }\end{array}$ & $\begin{array}{c}\text { \% Recovery } \\
\text { (PHE) }\end{array}$ & $\begin{array}{c}\text { \% RSD } \\
\text { IBU }\end{array}$ & $\begin{array}{c}\text { \% RSD } \\
\text { PHE }\end{array}$ \\
\hline $80 \%$ & 30 & 1.5 & 24 & 1.2 & $99.52 \%$ & $98.44 \%$ & $1.46 \%$ & $1.81 \%$ \\
\hline $100 \%$ & 30 & 1.5 & 30 & 1.5 & $99.71 \%$ & $99.12 \%$ & $0.94 \%$ & $1.12 \%$ \\
\hline $120 \%$ & 30 & 1.5 & 36 & 1.8 & $99.88 \%$ & $98.06 \%$ & $1.24 \%$ & $1.55 \%$ \\
\hline
\end{tabular}

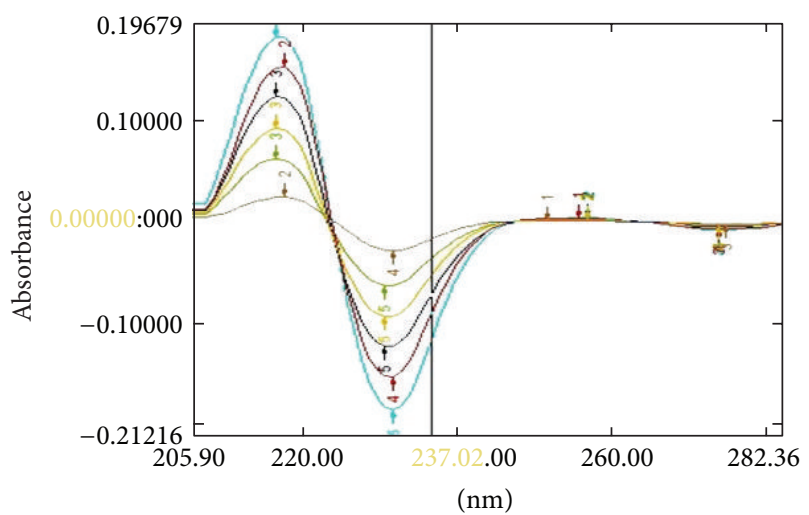

FIGURE 5: Overlain $\mathrm{D}^{1}$ spectrum of Ibuprofen (12-72 ppm) in $0.1 \mathrm{~N}$ $\mathrm{NaOH}$.

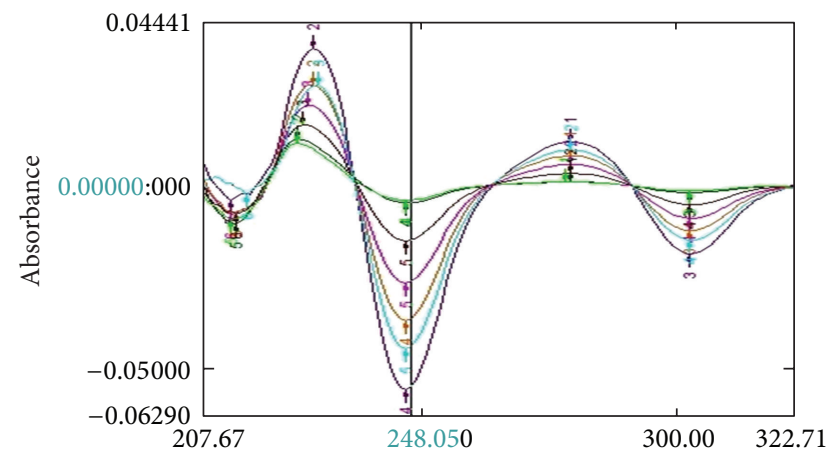

Figure 6: Overlain $\mathrm{D}^{1}$ spectrum of Phenylephrine HCL (1.5$22 \mathrm{ppm}$ ) in $0.1 \mathrm{~N} \mathrm{NaOH}$.

TABLE 3: Robustness (measuring absorbance at different time).

\begin{tabular}{lcccc}
\hline \multirow{2}{*}{ Time } & \multicolumn{2}{c}{ Absorbance } & \multicolumn{2}{c}{$\%$ Result } \\
& IBU & PHE & IBU & PHE \\
\hline $5 \mathrm{~min}$ & 0.04438 & 0.00406 & 100 & 100 \\
$10 \mathrm{~min}$ & 0.04431 & 0.00402 & 99.84 & 99.01 \\
$15 \mathrm{~min}$ & 0.04429 & 0.00402 & 99.79 & 99.01 \\
\hline
\end{tabular}

percent recovery found was $98.54 \%-100.88 \%$ and $98.79 \%-$ $101.66 \%$, respectively (Table 2 ). The intraday precision and interday precision were expressed in terms of relative standard deviation (RSD). For intraday and interday precision $\%$ RSD for IBU and PHE was found to be satisfactory. The interday precision at three concentration levels $(n=$ 3 ) on three different days was also evident with a low $\%$

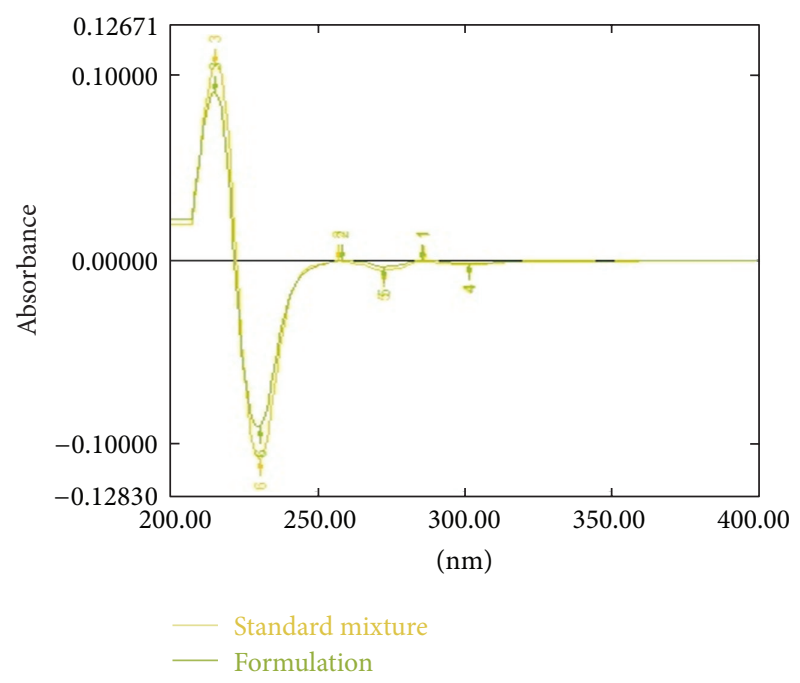

FIGURE 7: First derivative overlain spectra of IBU $(30 \mu \mathrm{g} / \mathrm{mL})$ and PHE $(1.5 \mu \mathrm{g} / \mathrm{mL})$ of marketed formulation, ADVIL and standard mixture.

TABLE 4: Results of validation parameters.

\begin{tabular}{lcc}
\hline Parameter & Ibuprofen & $\begin{array}{c}\text { Phenylephrine } \\
\text { HCL }\end{array}$ \\
\hline Linearity $(\mu \mathrm{g} / \mathrm{mL})$ & $12-72 \mu \mathrm{g} / \mathrm{mL}$ & $1.5-22 \mu \mathrm{g} / \mathrm{mL}$ \\
Correlation coefficient $\left(r^{2}\right)$ & 0.9972 & 0.9981 \\
Slope & 0.00016 & 0.00248 \\
Intercept & 0.00352 & 0.00038 \\
LOD $(\mu \mathrm{g} / \mathrm{mL})$ & 1.285596 & 0.443122 \\
LOQ $(\mu \mathrm{g} / \mathrm{mL})$ & 3.895744 & 1.342793 \\
Specificity & Specific & Specific \\
Robustness & Robust & Robust \\
\hline & Precision & \\
Intraday $(n=3)$ mean $\pm \%$ & $98.24 \pm 1.53$ & $98.23 \pm 1.63$ \\
RSD & & \\
Interday $(n=3)$ mean $\pm \%$ & $98.71 \pm 1.13$ & $98.12 \pm 1.43$ \\
RSD & &
\end{tabular}

RSD providing ruggedness of the method. The method is found to be specific (Figure 7). Also, small but deliberate changes do not affect the method, so method was found to be Robust (Table 3). Results of all validation parameters are shown in Table 4 . Hence, the proposed method was evaluated statistically and was validated in terms of linearity, accuracy, precision and ruggedness. The present work provides an 
accurate and sensitive method for the analysis of IBU and PHE in bulk and tablet formulation.

\section{Conclusion}

Based on the results obtained, it was found that the proposed method is accurate, reproducible, and economical and can be employed for routine quality control of Ibuprofen and Phenylephrine $\mathrm{HCl}$ in bulk and its dosage form.

\section{Acknowledgment}

The authors are heartily thankful to P.G. Department of Pharmaceutical Sciences, Sardar Patel University (Vallabh Vidyanagar, Gujarat, India), for funding entire project and providing the necessary facilities for research work.

\section{References}

[1] Martindale, The Complete Drug Reference, Pharmaceutical Press, London, UK, 33rd edition, 2002.

[2] V. E. Haikala, I. K. Heimonen, and H. J. Vuorela, "Determination of ibuprofen in ointments by reversed-phase liquid chromatography," Journal of Pharmaceutical Sciences, vol. 80, no. 5, pp. 456-458, 1991.

[3] I. Savić, G. Nikolić, and V. Banković, "Development and validation of spectrophotometric method for phenylephrine hydrochloride estimation in nasal drops formulations," Macedonian Journal of Chemistry and Chemical Engineering, vol. 27, no. 2, pp. 149-156, 2008.

[4] G. W. Schieffer and D. E. Hughes, "Simultaneous stabilityindicating determination of phenylephrine hydrochloride, phenylpropanolamine hydrochloride, and guaifenesin in dosage forms by reversed-phase paired-ion high-performance liquid chromatography," Journal of Pharmaceutical Sciences, vol. 72, no. 1, pp. 55-59, 1983.

[5] R. Gondalia, R. Mashru, and P. Savaliya, "Development and validation of spectrophotometric methods for simultaneous estimation of IBUPROFEN and PARACETAMOL in soft gelatin capsule by simultaneous equation method," International Journal of ChemTech Research, vol. 2, no. 4, pp. 1881-1885, 2010.

[6] D. A. Shah, D. J. Suthar, S. L. Baldania, U. K. Chhalotiya, and K. K. Bhatt, "Development and validation of liquid chromatographic method for estimation of ibuprofen and famotidine in combined dosage form," ISRN Analytical Chemistry, vol. 2012, Article ID 674392, 5 pages, 2012.

[7] B. Tsvetkova, I. P. Pencheva, A. B. Zlatkov, and P. T. Peikov, "Development and validation of RP-HPLC method for simultaneous determination of paracetamol and ibuprofen in fixed dose combinations," International Journal of Pharmaceutical Sciences Review and Research, vol. 16, no. 1, pp. 13-16, 2012.

[8] S. S. Chitlange, D. M. Sakarkar, S. B. Wankhede, and S. G. Wadodkar, "High performance thin layer chromatographic method for simultaneous estimation of ibuprofen and pseudoephedrine hydrochloride," International Journal of PharmTech Research, vol. 4, no. 4, pp. 1575-1580, 2012.

[9] W. D. Sam Solomon, R. A. Kumar, P. R. Vijai Anand, R. Sivakumar, and R. Venkatnarayanan, "Derivatized HPTLC method for simultaneous estimation of glucosamine and ibuprofen in tablets," Journal of Pharmaceutical Research and Health Care, vol. 2, no. 2, pp. 156-162, 2010.
[10] M. Maithani, R. Raturi, V. Gautam et al., "Development and validation of a RP-HPLC method for the determination of chlorpheniramine maleate and phenylephrine in pharmaceutical dosage form," International Journal of Comprehensive Pharmacy, vol. 1, no. 5, pp. 1-4, 2010.

[11] A. Marín, E. García, A. García, and C. Barbas, "Validation of a HPLC quantification of acetaminophen, phenylephrine and chlorpheniramine in pharmaceutical formulations: capsules and sachets," Journal of Pharmaceutical and Biomedical Analysis, vol. 29, no. 4, pp. 701-714, 2002.

[12] I. Muszalska, M. Zajac, G. Wrobel, and M. Nogowska, "UV/VIS spectrophotometric methods for determination of caffeine and phenylephrine hydrochloride in complex pharmaceutical preparations validation of the methods," Acta Poloniae Pharmaceutica, vol. 57, no. 4, pp. 247-252, 2000.

[13] S. Sheikh and S. A. Patni, "A validated, specific stability indicating reverse phase liquid chromatographic method for the simultaneous estimation of phenylephrine HCL, betamethasone valerate \& lignocaine HCL in pharmaceutical ointment," International Journal of Scientific and Research Publications, vol. 2, no. 12, 2012.

[14] P. V. Devarajan, M. H. Adani, and A. S. Gandhi, "Simultaneous determination of lignocaine hydrochloride and phenylephrine hydrochloride by HPTLC," Journal of Pharmaceutical and Biomedical Analysis, vol. 22, no. 4, pp. 685-690, 2000.

[15] S. Wankhede, K. Lad, and S. Chitlange, "Development and validation of UV-spectrophotometric methods for simultaneous estimation of cetirizine hydrochloride and phenylephrine hydrochloride in tablets," International Journal of Pharmaceutical Sciences and Drug Research, vol. 4, no. 3, pp. 222-226, 2012. 

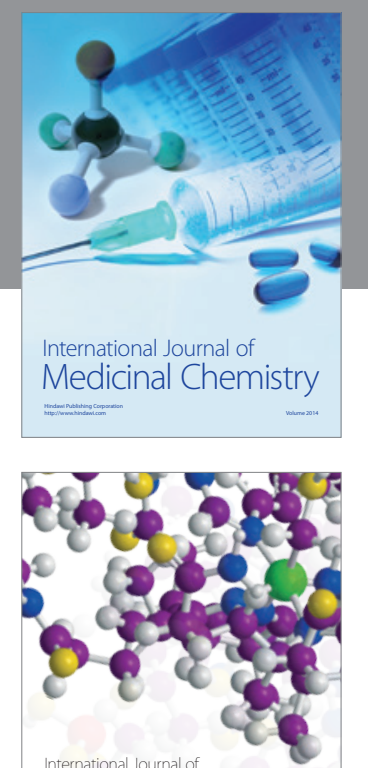

\section{Carbohydrate} Chemistry

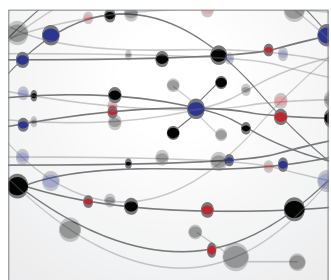

The Scientific World Journal
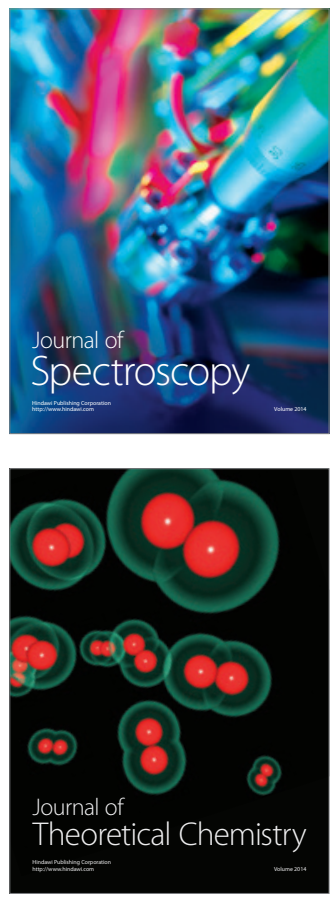
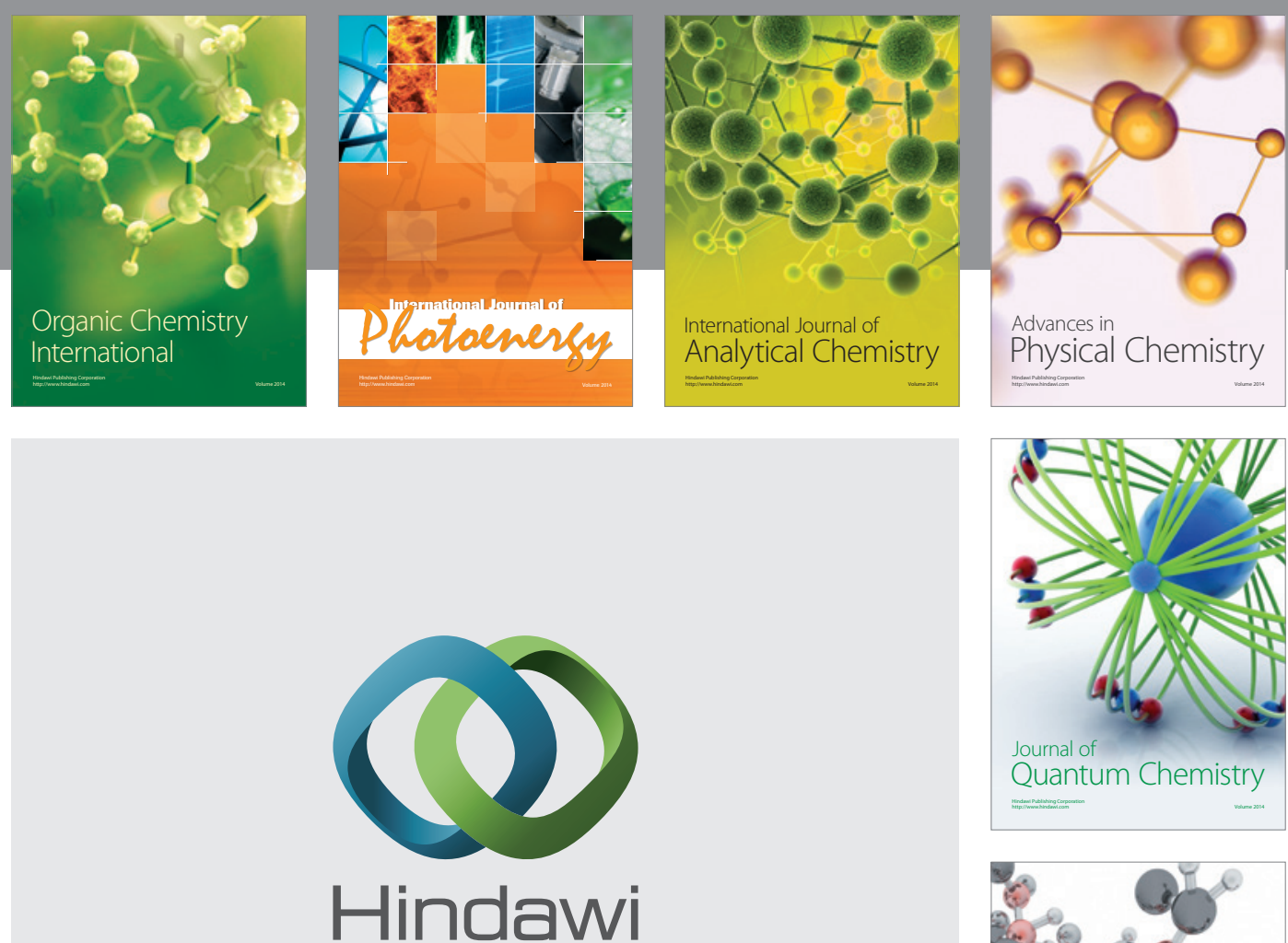

Submit your manuscripts at

http://www.hindawi.com

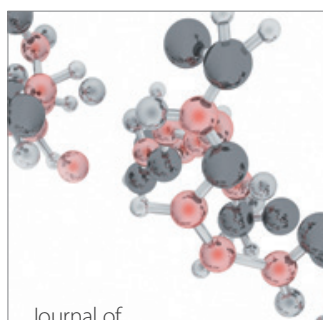

Analytical Methods

in Chemistry

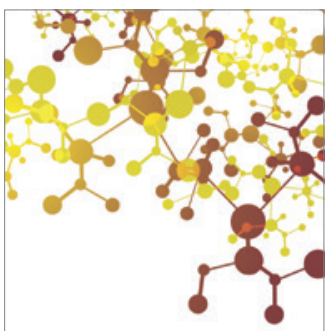

Journal of

Applied Chemistry

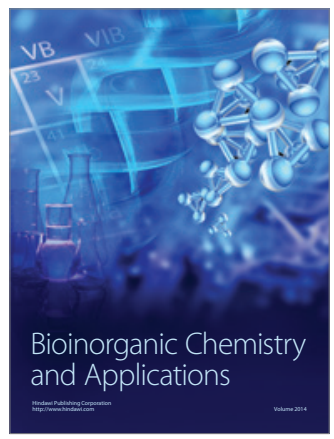

Inorganic Chemistry
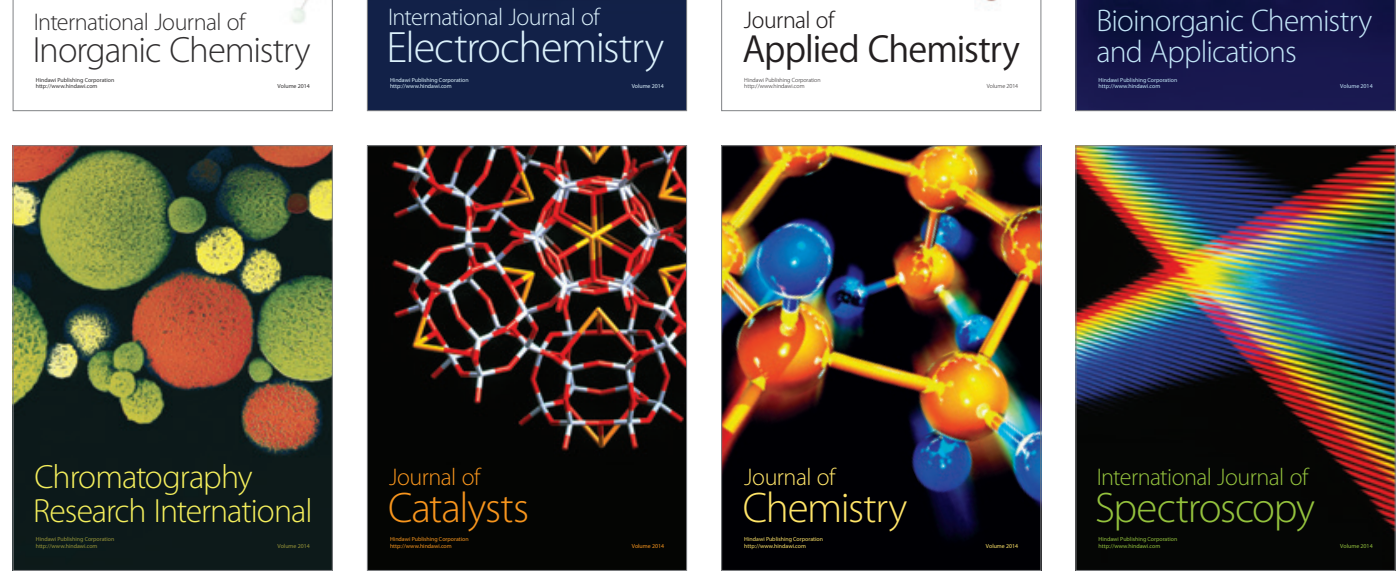